\title{
CORRIGENDUM
}

\section{A Marginalized Voice in the History \\ of 'Hindi' - Corrigendum}

\begin{abstract}
AISHWARJ KUMAR
doi: $10.1017 / S o 026749 X_{12000492}$ Published online by Cambridge University Press 14 March 2013
\end{abstract}

On page 3, the author would like to amend an incorrect date.

Following separate farmans (orders) for each of the three Mughal provinces of Bengal, Bihar and Orissa, with the Grant of Dewani rights the British took control of this vast region in 1865 .

Should read:

Following separate farmans (orders) for each of the three Mughal provinces of Bengal, Bihar and Orissa, with the Grant of Dewani rights the British took control of this vast region in 1765 .

\section{Reference}

Kumar, A. A Marginalized Voice in the History of 'Hindi'. Modern Asian Studies, published online 14 March 2013, doi:10.1017/Soo26749X1 2000492. 